\title{
Status of satellite precipitation retrievals
}

\author{
C. Kidd ${ }^{1}$ and V. Levizzani ${ }^{2}$ \\ ${ }^{1}$ Labortory for Atmospheres, NASA/GSFC, Greenbelt and ESSIC, University of Maryland, College Park, MD, USA \\ ${ }^{2}$ National Research Council, Institute of Atmospheric Sciences and Climate, Bologna, Italy
}

Received: 22 July 2010 - Published in Hydrol. Earth Syst. Sci. Discuss.: 18 October 2010

Revised: 28 February 2011 - Accepted: 1 March 2011 - Published: 5 April 2011

\begin{abstract}
Satellites offer an unrivalled vantage point to observe and measure Earth system processes and parameters. Precipitation (rain and snow) in particular, benefit from such observations since precipitation is spatially and temporally highly variable and with satellites overcoming some of the deficiencies of conventional gauge and radar measurements. This paper provides an overall review of quantitative precipitation estimation, covering the basis of the satellite systems used in the observation of precipitation, the dissemination and processing of this data, and the generation, availability and validation of these precipitation estimates. A selection of applications utilising these precipitation estimates are then outlined to exemplify the utility of such products.
\end{abstract}

\section{Introduction}

Precipitation is a major component of the global water and energy cycle, helping to regulate the climate system. Moreover, the availability of fresh water is vital to life on Earth. Measurement of global precipitation through conventional instrumentation uses networks of rain (or snow) gauges and, where available, weather radar systems. However, the global distribution of these is uneven: over the land masses the distribution and density of gauges is highly variable with some regions having "adequate" coverage while others have few or no gauges. Over the oceans few gauges exist, and those located on islands might be subject to local influences and therefore not representative of the surrounding ocean. The availability of historical precipitation data sets can also be problematic, varying in availability, completeness and consistency as well availability for near real-time analysis.

Correspondence to: $\mathrm{C}$. Kidd (chris.kidd@nasa.gov)
In 1963 the World Meteorological Organisation (WMO) established the World Weather Watch programme to coordinate the observational capability of surface and satellite observations, including the network of operational geostationary and polar-orbiting meteorological satellites called the Global Observing System (GOS; WMO, 2005). This system was charged with providing long-term stable data sets required by international organizations and the user community, consequently many of the early observations are compatible with current observing systems. Earth observation satellite sensors for meteorology are characterised by the need to provide frequent large-scale measurements resulting in large swath widths, resolutions finer than $1 \mathrm{~km}$ and systems capable of regular/frequent observations.

Geostationary (GEO) satellites are in an orbit such that they rotate around the Earth at the same speed as the Earth rotates, thus appearing stationary relative to a location on the Earth. This enables each geostationary satellite to view about one third of the Earth's surface on a frequent and regular basis. A total five geostationary satellites provide operational imagery: these currently include the Meteosat Second Generation satellites (MSG) from the European Organisation for the Exploitation of Meteorological Satellites (EUMETSAT), two Geostationary Operational Environmental Satellite (GOES) and the Japanese Multifunctional Transport Satellites (MTSAT) series. They share a number of common attributes: they typically carry visible (VIS) and infrared (IR) sensors with nadir resolutions of about $1 \times 1 \mathrm{~km}$ and $4 \times 4 \mathrm{~km}$, respectively, acquiring images nominally every $30 \mathrm{~min}$. These satellites provide an unrivalled platform for continual observation but are limited in the Polar Regions by the unfavourable viewing angle at high latitudes.

Low-Earth orbiting (LEO) satellites generally cross the Equator at the same local time on each orbit, providing about two overpasses per day. These satellites carry a range of instruments capable of precipitation retrievals, including multichannel VIS/IR sensors, and passive microwave (PMW)

Published by Copernicus Publications on behalf of the European Geosciences Union. 
sounders and imagers. Current operational polar-orbiting satellites include the National Oceanic and Atmospheric Administration (NOAA) series of satellites with NOAA-19 and EUMETSAT's MetOp series. Observations made by these satellites are typified by wide swaths $(2800 \mathrm{~km})$ with resolutions of about $1 \mathrm{~km}$.

A number of other operational and "research and development" satellite missions are also used for precipitation estimation. The Defense Meteorological Satellite Program (DMSP) satellites series of Special Sensor Microwave/Imager (SSM/I) and Special Sensor Microwave Imager-Sounder (SSMIS) provide measurements of naturally emitted microwave (MW) radiation from the Earth and its atmosphere. The AQUA satellite includes the PMW Advanced Microwave Scanning Radiometer-Earth Observing System (EOS) (AMSR-E). PMW sensors typically have swath widths in the order of $1500 \mathrm{~km}$ and resolutions, variable with observational frequency, of between $4 \mathrm{~km}$ and about $50 \mathrm{~km}$. In addition, the AQUA mission also carries the VIS/IR MODerate-resolution Imaging Spectroradiometer (MODIS), the latter also carried onboard the TERRA satellite. The MODIS instrument, with 36 VIS/IR spectral bands enables information on cloud properties (such as cloud drop radii and phase) to be retrieved.

The Tropical Rainfall Measuring Mission (TRMM), launched in 1997, was the first dedicated precipitation satellite and has been key in the development and improvement of satellite rainfall estimation techniques. It carries a range of instruments which allow direct comparisons to be made between VIS, IR, PMW and active MW observations. The Precipitation Radar (PR) was the first spaceborne precipitation radar, capable of sampling precipitation both vertically and horizontally, although with a limited swath of $210 \mathrm{~km}$. Other instruments include the TRMM Microwave Imager (TMI), the Visible and InfraRed Scanner (VIRS), and the Lightning Imaging Sensor (LIS). The non sun-synchronous nature of its orbit allows samples across the full diurnal cycle to be made. Other current active MW sensors include the nadir-pointing Cloud Profiling Radar (CPR) on the CloudSat mission.

\section{Precipitation retrieval methods}

Satellite estimates of precipitation can be derived from a range of observations from many different sensors. The retrieval methodologies fall primarily into three main categories based upon type of observation, primarily VIS/IR techniques, PMW techniques and multi-sensor techniques.

\subsection{VIS/IR methods}

In the VIS part of the spectrum clouds appear relatively bright against the surface of the Earth due to their high albedo. Rainfall can be inferred from VIS images since bright clouds tend to be thick, and thick clouds are more likely to be associated with rainfall. However, the relationship between brightness and rainfall is poor and consequently VIS imagery is usually only used in conjunction with other observations. Cloud-top texture derived from VIS imagery can provide useful information: stratus is typically smooth, while convective clouds tend to be more "lumpy". Properties of cloud-top particles, (size, phase) can be obtained from multi-channel near-IR (nIR) data. The use of reflected/emitted radiances around 1.6, 2.1 and $3.9 \mu \mathrm{m}$ have proved very useful in studying the microphysical properties of clouds, despite some being restricted to full daylight operations. The Clouds-Aerosols-Precipitation Satellite Analysis Tool (CAPSAT; Lenksy and Rosenfeld, 2008) classifies imagery using lookup tables specifically tailored to "day microphysical" and "night microphysical" conditions, allowing cloud microphysics-based scene classification useful for rain area delineation.

IR imagery that measures the thermal emissions from objects is potentially more useful, and is available night and day. Heavier rainfall tends to be associated with larger, taller clouds with colder cloud tops. By observing cloud top temperatures (CTT) a simple rainfall estimate can be derived. However, the CTT to rainfall relationship is indirect, with significant variations in the relationship during the lifetime of a rainfall event, between rain systems, and between climatological regimes. Nevertheless, IR-based techniques benefit from a degree of simplicity coupled with the $24 \mathrm{~h}$ availability of the data. Barrett and Martin (1981) provide a comprehensive overview of the early algorithms and methods. An example of these techniques includes the Global Precipitation Index (GPI; Arkin and Meisner, 1987).

Multi-channel techniques use combinations of available VIS/IR observations: these include the GOES Multi-Spectral Rainfall Algorithm (GMSRA; Ba and Gruber, 2001) that utilises 5 channels from the GOES satellite to extract information on the cloud and rain extent, derive rainfall and apply corrections depending upon the type of cloud/precipitation regime, while Roebeling and Holleman (2009) developed the precipitation properties (PP) algorithm to utilise cloud physical properties from MSG.

Artificial neural networks (ANN) have also been usefully employed: Behrangi et al. (2009) devised a method for improved rain/no rain detection. These results show that during daytime significant improvements in rain/no rain detection can be made.

\subsection{Passive microwave methods}

The Earth naturally emits low levels of MW radiation which may be passively sensed by radiometers. This radiation is primarily attenuated by the presence of precipitation-sized particles. Two processes can be used to identify precipitation: emission from rain droplets which lead to an increase in MW radiation and scattering caused by precipitating ice particles which leads to a decrease in MW radiation. The 
background radiometric signal over water is low and constant (emissivity, $\varepsilon \sim 0.4-0.5$ ), therefore additional emissions from precipitation can be used to identify and quantify the rainfall using low-frequency channels $(<20 \mathrm{GHz})$. Over land, the surface has a much higher background emissivity (c-0.9) and consequently emissions from hydrometeors cannot be reliably measured. Here, scattering caused by ice particles, resulting in a decrease in received radiation at highfrequencies $(>35 \mathrm{GHz}$ ), must be utilised. Over land stringent schemes must be employed to ensure the surface background does not contaminate any precipitation retrieval: Ferraro et al. (1998) present a discussion on methods that identify areas of rain, snow cover, deserts, and semiarid conditions over land, and rain, sea ice, strong surface winds, and clear, calm conditions over ocean.

PMW precipitation retrieval algorithms can therefore be generally classified into (1) "emission" type algorithms (e.g., Wilheit et al., 1991); (2) "scattering" type algorithms (e.g., Spencer et al., 1989), and; (3) "multichannel inversion" algorithms (e.g., Bauer, 2001). These can in turn be divided into empirical techniques which are calibrated against surface data sets (and incorporate beam-filling/inhomogeneous field-of-view, absolute calibration issues, resolution differences), and physical techniques that minimise the difference between modelled and the observed radiation. More successful physical techniques use a priori data bases of which compare the satellite observations with model-generated atmospheric profiles. The main advantage of physical techniques is that they provide more information about the precipitation system than just the surface rainfall.

Additional techniques have been developed that rely upon the training of ANN to derive relationships between the satellite passive microwave observations and surface rainfall: in one such technique, Capacci and Porcu (2009) used an ANN with 5 rain classes training with ground radar network to improve the AMSR-E rain area detection.

High-frequency PMW observations from, for example, the Advanced Microwave Sounding Unit-B (AMSU-B) instrument, provide additional observations and the ability to retrieve precipitation over problematic surface backgrounds, such as coastlines and snow/ice. Reference Chen and Staelin (2003) constructed one of the first global techniques to exploit these sounding channels to derive precipitation rates at 15- and 50-km resolution from AIRS, AMSU and the Humidity Sounder for Brazil (HSB) using an ANN. Laviola and Levizzani $(2008,2009)$ proposed a thresholding technique, the Water vapour Strong Lines at $183 \mathrm{GHz}$ (183-WSL) algorithm, which first discriminates between rain and no-rain areas and then retrieves precipitation divided into convective and stratiform.

The main drawback of PMW-based techniques is that observations are currently only available from low-Earth orbiting satellites, typically resulting in two observations per day per satellite. In addition, the spatial resolution of the low frequency channels that are used over the ocean is of the order of $50 \times 50 \mathrm{~km}$, while for the higher-frequency channels used over the land resolutions are typically no better than $10 \times 10 \mathrm{~km}$.

\subsection{Active microwave methods}

Active MW techniques are perhaps the most direct method of precipitation estimation. However, the use of spaceborne precipitation estimation has been very limited with only the TRMM PR being specifically designed for retrieving precipitation characteristics. As with all radar systems, the PR relies upon the interpretation of the backscatter of radiation from precipitation, which is broadly proportional to the number of precipitation-sized particles and therefore the intensity. However, the precipitation intensity to backscatter relationship is not constant. Nevertheless, the PR has been extensively used as a primary source of high-quality rainfall estimates for evaluating the differences of rainfall regimes over land and over the ocean, for example, Ikai and Nakamura (2003) found systematic differences between TMI and PR rainfall estimates, (see also Furuzawa and Nakamura, 2005). The future GPM mission (Hou et al., 2008) will include a dual-wavelength precipitation radar (DPR) at 13.6 and $35.5 \mathrm{GHz}$, which has a greater sensitivity necessary to detect light rain and snow as low as $0.3 \mathrm{~mm} \mathrm{~h}^{-1}$.

Combined radar-radiometer algorithms have been developed to exploit their intrinsic ambiguities. Grecu et al. (2004) investigated vertical profiles of precipitation from multifrequency, multi-resolution active and passive MW observations. Viltard et al. (2006) proposed a rainfall retrieval technique for the TMI using a database of about 35000 brightness temperature $\left(T_{\mathrm{b}}\right)$ vectors collocated with the corresponding PR rain rate profiles.

Recently the CloudSat Cloud Profiling Radar (CPR; Stephens et al., 2008) has shown a precipitation retrieval capability. The CPR operates at $94 \mathrm{GHz}$ and is much more sensitive to cloud hydrometeors, tending to saturate in regions of dense cloud or rainfall. However, through the use of attenuation-correction algorithms and surface reflectivity modelling, it has proved to be very useful in the identification of light rainfall and snowfall. Haynes et al. (2009) demonstrated a notable rainfall retrieval potential at mid-latitudes over the ocean. For rain rates less than $0.8 \mathrm{~mm} \mathrm{~h}^{-1}$ the CPR produces nearly three times the rainfall occurrence than that sensed by the TRMM PR, resulting in the production of a more representative precipitation intensity distribution function.

\subsection{Multi-sensor techniques}

A growing number of techniques are being developed to exploit the synergy between the polar-orbiting PMW retrievals (infrequent, more direct) with the geostationary observations (frequent, less direct). Techniques have been developed to adjust the IR, or generate calibration curves to map IR 
radiances using the other data sets, such as radar, gauge or other satellite data set. The TRMM Multi-Satellite Precipitation Analysis (TMPA; Huffman et al., 2007) ingests data from PMW imaging and sounding sensors and geostationary IR data with adjustments made for the different satellite retrievals before combining them into a single precipitation product. The Climate Prediction Center Merged Analysis of Precipitation (CMAP; Xie and Arkin, 1998) incorporates satellite IR along with gauge and re-analysis data from the National Centers for Environmental Prediction (NCEP) and NCAR. Other techniques include the Passive Microwave InfraRed technique (PMIR; Kidd et al., 2003), the Naval Research Laboratory (NRL) technique (Turk et al., 2000), and the Global Satellite Mapping of Precipitation (GSMaP; Kubota et al., 2007). Other techniques have used ANNs to derived precipitation estimates through combining information from multi-channel and multi-sensor observations like the Precipitation Estimation from Remotely Sensed Information using Artificial Neural Network (PERSIANN; Hsu et al., 1997).

These techniques are ultimately limited by the indirectness of the IR to sense rainfall itself. However, the IR data can provide a reasonable measure of cloud movement, which can then be used to advect or morph the more direct PMW data between the successive satellite overpasses. Such techniques came under the category of motion-based techniques. Examples include the Climate Prediction Center Morphing technique (CMORPH; Joyce et al., 2004). More complex techniques use a combination of satellite observations and modelling to provide rainfall estimates: the Lagrangian Model (LMODEL) proposed by Bellerby et al. (2009) is based on a conceptual cloud-development model driven by GEO satellite imagery, locally updated using MW-based rainfall measurements from LEO platforms. More recently Behrangi et al. (2010) have developed the REFAME technique that combines advection and cloud development together into one technique.

Lightning data, from ground based detection networks or from space sensors, has proved useful in improving precipitation retrievals: Grecu et al. (2000) developed a technique combining cloud-to-ground lightning and satellite IR data for convective rainfall estimation while TRMM PR, TMI and LIS data have been combined over the Tropics and the subTropics to examine the precipitation features.

The longevity of some data sets is starting to allow longterm data sets to be established: the GPCP products start in 1979 due to the availability of well-calibrated satellite IR data sets, with PMW data being incorporated from 1987. The Cooperative Institute for Climate Studies (CICS) has developed the CICS High-Resolution Optimally Interpolated Microwave Precipitation from Satellites (CHOMPS; Joseph et al., 2009) to provide a tool for studying longer modes of climate variability. The availability of these data sets has also led to "operational" precipitation products to be routinely produced through concerted programmes, such as the EUMETSAT Satellite Applications Facility on Support to Operational Hydrology and Water Management (H-SAF; Bizzari et al., 2008).

\section{Applications}

Many applications have been able to directly use precipitation products generated from satellite observations. New satellite systems, such as the geostationary data from MSG SEVIRI, have greatly enhanced frequency of observation and the multi-spectral potential of rainfall retrievals (Levizzani et al., 2001). Many data sets are now readily available in near real time (Turk et al., 2008) and have raised the potential for improved and new applications.

\subsection{Hydrology and the water cycle}

The usability of satellite-derived products relies upon the data being available in real time (or very near real time). Precipitation products, such as the GPCP monthly precipitation analysis, have been used for a range of applications including flood and landslide prediction and drought monitoring. The effective use of satellite precipitation estimates for hydrological and water resource applications (e.g. Sorooshian et al., 2009; Hossain and Anagnostou, 2004) is very much dependent upon the type of application and the accuracy, spatial resolution, temporal resolution and latency of the estimates: different applications have different data requirements. Hydrological requirements for precipitation estimates can be divided into two main categories: high resolution/short-duration estimates and lowerresolution/longerterm estimates. Flash flood events, with rapid catchment response necessitate fine spatial and temporal scales together with timely delivery of the estimates. The availability of observations at $4 \times 4 \mathrm{~km}$ every $15 \mathrm{~min}$ is available from some of the GEO satellites, with the potential for $1 \times 1 \mathrm{~km}, 1 \mathrm{~min}$ imagery in rapid scan mode. However, due to the indirect nature of the cloud-top to surface rainfall relationship such estimates are subject to error. Nevertheless, techniques such as the Hydro-Estimator based upon the GOES IR observations (Scofield and Kuligowski, 2003) have proved useful for operational use over the United States. Fluvial flooding and water resources are characterised by relatively long lead times, therefore satellite derived precipitation products can be of great benefit. Static surface parameters (e.g., geology, soil type, relief), dynamic surface parameters (e.g., soil moisture, vegetation, groundwater) as well as the precipitation (satellite and surface) and meteorological/climatological conditions can be brought together on a global scale to provide a comprehensive hydrometeorological data base. 


\subsection{Process studies}

The availability of finer resolution observations has also provided new insights into precipitation events and process. The capability of the TRMM PR to provide long-term (available since 1997), high spatial resolution precipitation measurements has been demonstrated by Kidd and McGregor (2007). Zipser et al. (2006) looked at the characteristics of precipitation from TRMM observations, highlighting the distribution of intense precipitation regimes. Although use of satellite estimates for flash flood events is challenging, observations, such as those from TRMM, can provide information on the occurrence of rainfall extremes and characteristics of the local meteorology that can help improve short-term forecasting of such events. In addition, such climatological products also provide useful information for geomorphological processes that are often rainfall-dependent.

Studies of anthropogenic influences of precipitation have also been studied: Shepherd et al. (2002) investigated the distribution of rainfall around US cities while Givati and Rosenfeld (2004) investigated the suppression of rainfall and snow by air pollution.

\subsection{Snowfall estimation}

Several studies have demonstrated the feasibility of estimating snow from space using high frequency channels (e.g., Liu and Curry, 1997). At high frequencies $(>100 \mathrm{GHz})$ water vapor screens the surface background while the sensitivity to frozen hydrometeors is significant. Combined cloud radar and PMW radiometer data have been used for snowfall detection: see Grecu and Olsen (2008) and Evans et al. (2005). The algorithm, based on physical cloud-resolving models, simulates cloud radar and millimeter-wave radiometer observations from basic atmospheric variables such as hydrometeor content, temperature, and relative humidity profiles and works with an optimal estimation technique to retrieve these variables from actual observations.

\subsection{Climate studies}

The use of long-term satellite precipitation data sets for climate studies is now emerging. However, data set continuity is an issue with known errors both from and between individual sensors (such as scan-angle dependencies and orbital drift). Initial comparisons between model re-analyses and satellite precipitation data sets show significant longterm differences in the trends of global precipitation as well as year-on-year differences with the GPCP analysis producing an average of $\sim 2.6 \mathrm{~mm} \mathrm{~d}^{-1}$ globally compared with the NCEP reanalysis of $\sim 3.2 \mathrm{~mm} \mathrm{~d}^{-1}$. Importantly, most satellite-based long-term precipitation studies, incorporating corrections for multi-satellite/sensor data sets, show little or no trend in global precipitation (Gruber and Levizzani, 2008). Positive (negative) correlations were found (Adler et al., 2008) between temperature and precipitation over tropical oceans (lands) with ENSO being the dominant factor in these interannual tropical relations. Away from the tropics, particularly in the Northern Hemisphere mid-high latitudes, this relationship becomes much more complicated.

\section{Precipitation product validation}

In the late 1980's the WetNet project encouraged the interaction of scientists working on the then new SSM/I PMW data sets, including the validation of the rainfall retrievals. As a result a series of Precipitation Intercomparison Projects (PIP) were organised: the first and third projects concentrated upon estimates derived at monthly, $0.25 \times 0.25^{\circ}$ resolutions (Adler et al., 2001) whilst the second investigated individual instantaneous case studies over a variety of different meteorological situations and geographically diverse regions. Parallel to these projects was the Algorithm Inter-comparison Programme (AIP; Ebert and Manton, 1998) which encompassed a range of precipitation estimates from various satellite observation sources as well as model output for specific co-ordinated observation periods.

The main conclusion from the PIP and AIP intercomparisons was that PMW techniques were clearly better than IR techniques for instantaneous estimates due to their more direct observation of the rainfall. However, this advantage deteriorated over longer time scales due to the poorer sampling of PMW observations compared to the IR-based techniques. The combined IR-PMW techniques, which were expected to do well, did not show a clear advantage at this stage over the IR-alone techniques. It was also noted however, that the performance of all the algorithms were very much dependent upon common underlying factors, such as surface background conditions, seasons/latitude and meteorological conditions, and therefore no single algorithm, technique or methodology could be deemed superior to any other.

Validation data sets, or perhaps more correctly, surface reference data sets, generally rely upon available gauge data or radar depending upon the temporal and spatial scales over which the estimates were being evaluated. In all cases, the surface data sets arenot necessarily the "truth" since many factors affect the true value. However, through the careful selection of data, inconsistencies or shortcomings can be reduced (e.g. Villarini et al., 2008). Specific ground validation campaigns (e.g., Wolff et al., 2005) identify specific locations for the collection of (primarily) radar and gauge data sets: these campaigns are generally designed for improving the physical retrievals of the satellite estimates. However, more recent and on-going validation rely upon mainly statistical inter-comparisons with surface data sourced from routinely available data sets, such as the US NEXRAD or the European Nimrod and OPERA radar products.

The International Precipitation Working Group (IPWG) provides a focus for operational and research satellite-based 
quantitative precipitation measurement issues and challenges, addressing a number of key objectives described by Turk and Bauer (2006). The IPWG currently provides ongoing near real time validation of quasi-operational and operational satellite estimates, as well as NWP model outputs (see Ebert et al., 2007). The current IPWG inter-comparison regional sites provide validation statistics for daily, $0.25^{\circ}$ resolution estimates over the US, Europe, Australia, Japan and South America, using radar and/or gauge data as their surface ground truth. Other validation efforts, which operate "offline" include South Korea, China, South Africa, Ethiopia. Results show that the NWP models and motion-based satellite techniques outperform the standard satellite estimates of precipitation in cold-season environments (e.g., during midlatitude winters). However, warm-season performance studies tend to favour the satellite techniques since these can capture the location and timing of convective precipitation better than existing NWP models. More recently, the Program for the Evaluation of High-Resolution Precipitation Products (PEHRPP) has been established to characterise the errors in high-resolution precipitation products $\left(<0.25 \times 0.25^{\circ}\right.$ and 3 hourly or less) over different spatial, temporal, regional and climate scales.

Investigations into the errors associated with rainfall estimates have started to be addressed. Bowman (2005) studied the spatial and temporal averaging errors of the TRMM precipitation retrievals and ocean gauge data over the tropical Pacific Ocean, while Gebremichael and Krajewski (2005) investigated the sampling effects of rainfall from surface data sets.

The propagation of such errors hydrological models was addressed by Hossain and Anagnostou (2004) who examined TRMM PMW and IR-based satellite rainfall retrievals for flood prediction using a probabilistic error model, while Hossain et al. (2004) performed a sensitivity analysis of satellite rainfall retrieval and sampling error on flood prediction uncertainty. Hossain and Huffman (2008) examined the set of error metrics for satellite rainfall data that can advance the hydrologic application of new-generation, highresolution rainfall products over land.

\section{Conclusions}

Precipitation products derived from satellite observations have reached a good level of maturity over the last decade. Ongoing research and development continues to address the accuracy and the resolution (temporal and spatial) of these products, along with the generation of error estimates vital to hydrological modelling and water resource assessment. This involves both the continuation of operational missions, critical to the routine observation of the weather, and provision of long term data sets critical for climate monitoring and impact assessment (Asrar et al., 2001; NRC, 2008).
A number of recommendations (see Kidd et al., 2010 and Huffman and Klepp, 2011) for future research and development of precipitation estimation from satellite observations can be identified. First, the availability of high quality satellite data sets in near real time is of critical importance, with the continuation of merged global composites, such as the Global-IR data set (Janowiak et al., 2001). However, existing data (including model data) also requires permanent archives and reprocessing where necessary to ensure longterm usability of the data sets. Second, the generation of precipitation products for the user community is necessary for operational use. The distribution of precipitation products through existing networks should be encouraged, while data and software should be made freely available. Further exploitation of satellite precipitation observations and products for data assimilation is needed since relatively little data is currently exploited.

Future activities should also build upon the existing strong intercomparison/validation record of the IPWG, with the inclusion of precipitation products from models encouraged. The usefulness of different validation tools should be assessed, while data sets should be assigned a quality index. Validation should also be extended to the use of hydrological impact studies and should be also be used as a means of validating the precipitation products. Of particular importance for improving precipitation retrievals is the identification and retrieval of frozen precipitation, through improved radiative transfer modelling and the combined use of both active and passive observations (e.g., CloudSat, AMSR-E and AMSUB).

New satellites systems and sensors are planned with the potential to improve precipitation retrievals. The present spaceborne radar systems (TRMM PR and CloudSat CPR) will be augmented by the upcoming radars on the European Space Agency's (ESA) Clouds, Aerosol and Radiation Explorer (EarthCare) and the GPM-core satellites. New lightning sensors will be exploited on new geostationary satellites including the US GOES-R, the European Meteosat Third Generation (MTG) and the Chinese FY-4. In particular, the Committee on Earth Observation Satellites (CEOS), declared precipitation to be an important measurement and identified the NASA and the Japan Aerospace Exploration Agency (JAXA) GPM mission as a prototype of the Global Earth Observation System of Systems (GEOSS): this mission will extend our capabilities both in coverage and instrumentation to advance precipitation research. These missions, combined with others such as the Japanese GCOM-W and the French-Indian Megha-Tropiques mission will contribuye to enhancing our observational capacity for global precipitation measurement.

Edited by: P. van Oevelen 


\section{References}

Adler, R. F., Kidd, C., Petty, G., Morrissey, M., and Goodman, H. M.: Intercomparison of global precipitation products: the third Precipitation Intercomparison Project (PIP-3), B. Am. Meteorol. Soc., 82, 1377-1396, 2001.

Adler, R. F., Hong, Y., and Huffman, G. J.: Flood and landslide applications of high time resolution satellite rain products, Proc. 3 Int, Precipitation Working Group Workshop, Melbourne, 23-27 October 2006, available at: http://www.isac.cnr.it/ ipwg/ meetings/melbourne-2006/melbourne2006-pres.html, 2008.

Arkin, P. A. and Meisner, B. N.: The relationship between largescale convective rainfall and cold cloud over the western hemisphere during 1982-1984, Mon. Weather Rev., 115, 51-74, 1987.

Asrar, G., Kaye, J. A., and Morel, P.: NASA Research strategy for Earth System Science: climate component, B. Am. Meteorol. Soc., 82, 1309-1329, 2001.

Ba, M. B. and Gruber, A.: GOES multispectral rainfall algorithm (GMSRA), J. Appl. Meteorol., 40, 1500-1514, 2001.

Barrett, E. C. and Martin, D. W.: The use of satellite data in rainfall monitoring, Academic Press, London, p. 340, 1981.

Bauer, P.: Over-ocean rainfall retrieval from multisensory data or the Tropical Rainfall Measuring Mission, Part I: Design and evaluation of inversion databases, J. Atmos. Ocean. Techn., 18, 1315-1330, 2001.

Behrangi, A., Hsu, K.-L., Imam, B., Sorooshian, S., and Kuligowski, R.: Evaluating the utility of multispectral information in delineating the areal extent of precipitation, J. Hydrometeorol., 10, 684-700, 2009.

Behrangi, A., Imam, B., Hsu, K., Sorooshian, S., Bellerby, T. J., and Huffman G. J.: REFAME: Rain estimation using forwardadjested advection of microwave estimates, J. Hydrometeorol., 11, 1305-1321, 2010.

Bellerby, T., Hsu, K.-L., and Sorooshian, S.: MODEL: a satellite precipitation methodology using cloud development modeling, Part I: Algorithm construction and calibration, J. Hydrometeorol., 10, 1081-1095, 2009.

Bizzarri, B. and the H-SAF Consortium: Update on the status of precipitation products in the EUMETSAT Satellite Application Facility on Support to Hydrology and Water Management, Proc. 4th IPWG Workshop on Precipitation Measurements, Beijing, 13-17 Oct., EUMETSAT, EUMETSAT, Darmstadt, p. 54, ISBN:978-92-9110-085-9, 2008.

Bowman, K. P.: Comparison of TRMM precipitation retrievals with rain gauge data from ocean buoys, J. Climate, 18, 178-190, 2005.

Capacci, D. and Porcu, F.: Evaluation of a satellite multispectral VIS-IR daytime statistical rain-rate classifier and comparison with passive microwave rainfall estimates, J. Appl. Meteorol. Climatol., 48, 284-300, 2009.

Chen, F. W. and Staelin, D. H.: AIRS/AMSU/HSB precipitation estimates, IEEE T. Geosci. Remote, 41, 410-417, 2003.

Ebert, E. E. and Manton, M. J.: Performance of satellite rainfall estimation algorithms during TOGA COARE, J. Atmos. Sci., 55, 1537-1557, 1998.

Ebert, E. E., Janowiak, J. E., and Kidd, C.: Comparison of nearreal-time precipitation estimates from satellite observations and numerical models, B. Am. Meteorol. Soc., 88, 47-64, 2007.

Evans, K. F., Wang, J. R., Racette, P. E., Heymsfield, G. and Li, L. H.: Ice cloud retrievals and analysis with the compact scanning submillimeter Imaging radiometer and the cloud radar sys- tem during CRYSTAL FACE, J. Appl. Meteorol., 44, 839-859, 2005.

Ferraro, R., Smith, E. A., Berg, W., and Huffman, G. J.: A screening methodology for passive microwave precipitation retrieval algorithms, J. Atmos. Sci., 55, 1583-1600, 1998.

Furuzawa, F. A. and Nakamura, K.: Differences of rainfall estimates over land by Tropical Rainfall Measuring Mission (TRMM) Precipitation Radar (PR) and TRMM Microwave Imager (TMI) dependence on storm height, J. Appl. Meteorol., 44, 367-382, 2005.

Gebremichael, M. and Krajewski, W. F.: Effect of temporal sampling on inferred rainfall spatial statistics, J. Appl. Meteorol., 44, 1626-1633, 2005.

Givati, A. and Rosenfeld, D.: Quantifying precipitation suppression due to air pollution, J. Appl. Meteorol., 43, 1038-1056, 2004.

Grecu, M. and Olson, W. S.: Precipitating snow retrievals from combined airborne cloud radar and millimeter-wave radiometer observations, J. Appl. Meteorol. Climatol., 47, 1634-1650, 2008.

Grecu, M., Anagnostou, E. N., and Adler, R. F.: Assessment of the use of lightning information in satellite infrared rainfall estimation, J. Hydrometeorol., 1, 211-221, 2000.

Grecu, M., Olson, W. S., and Anagnostou, E. N.: Retrieval of precipitation profiles from multiresolution, multifrequency active and passive microwave observations, J. Appl. Meteorol., 43, 562-575, 2004.

Gruber, A. and Levizzani, V. (Eds.): Assessment of global precipitation products. WCRP Series Report No. 128 and WMO TD-No. 1430, available at: http://wcrp.wmo.int/documents/ AssessmentGlobalPrecipitationReport.pdf, 55 pp., 2008.

Haynes, J. M., L'Ecuyer, T. S., Stephens, G. L., Miller, S. D., Mitrescu, C., Wood, N. B., and Tanelli, S.: Rainfall retrieval over the ocean with spaceborne W-band radar, J. Geophys. Res., 114, D00A22, doi:10.1029/2008JD009973, 2009.

Hossain, F. and Anagnostou, E. N.: Assessment of current passive-microwave- and infraredbased satellite rainfall remote sensing for flood prediction, J. Geophys. Res., 109, D07102, doi:07110.01029/02003JD003986, 2004.

Hossain, F. and Huffman, G.: Investigating error metrics for satellite rainfall data at hydrologically relevant scales, J. Hydrometeorol., 9, 563-575, 2008.

Hossain, F., Anagnostou, E. N., and Dinku, T.: Sensitivity analyses of satellite rainfall retrieval and sampling error on flood prediction uncertainty, IEEE T. Geosci. Remote, 42, 130-139, 2004.

Hou, A. Y., Skofronick-Jackson, G., Kummerow, C. D., and Shepherd, J. M.: Global precipitation measurement, in: Precipitation: Advances in Measurement, Estimation and Prediction, edited by: Michaelides, S., Springer, Springer-Verlag, Berlin, 131-169, 2008.

Hsu, K., Gao, X., Sorooshian, S., and Gupta, H. V.: Precipitation estimation from remotely sensed information using artificial neural networks, J. Appl. Meteorol., 36, 1176-1190, 1997.

Huffman G. J. and Klepp, C.: Meeting Summary: Fifth workshop of the International Precipitation Working Group, B. Am. Meteorol. Soc., submitted, 2011.

Huffman, G. J., Adler, R. F., Bolvin, D. T., Gu, G., Nelkin, E. J., Bowman, K. P., Hong, Y., Stocker, E. F., and Wolff, D. B.: The TRMM Multisatellite Precipitation Analysis (TMPA): quasi-global, multiyear, combined-sensor precipitation estimates at fine scales, J. Hydrometeorol., 30(8), 38-55, 2007. 
Ikai, J. and Nakamura, K.: Comparison of rain rates over the ocean derived from TRMM Microwave Imager and Precipitation Radar, J. Atmos. Ocean. Techn., 20, 1709-1726, 2003.

Janowiak, J. E., Joyce, R. J., and Yarosh, Y.: A real-time global half-hourly pixel-resolution infrared dataset and its applications, B. Am. Meteorol. Soc., 82, 205-217, 2001.

Joseph, R., Smith, T. M., Sapiano, M. R. P., and Ferraro, R. R.: A new high-resolution satellite-derived precipitation dataset for climate studies, J. Hydrometeorol., 10, 935-952, 2009.

Joyce, R. J., Janowiak, J. E., Arkin, P. A., and Xie, P.: CMORPH: a method that produces global precipitation estimates from passive microwave and infrared data at high spatial and temporal resolutions, J. Hydrometeorol., 5, 487-503, 2004.

Kidd, C. and McGregor, G. R.: Observation and characterisation of rainfall over Hawaii and surrounding region from the Tropical Rainfall Measuring Mission, Int. J. Climatol., 27, 541-553, 2007.

Kidd, C., Ferraro, R., and Levizzani, V.: The fourth international precipitation group workshop. B. Am. Meteorol. Soc., 91, 10951099, 2010.

Kidd, C., Kniveton, D. R., Todd, M. C., and Bellerby, T. J.: Satellite rainfall estimation using a combined passive microwave and infrared algorithm, J. Hydrometeorol., 4, 1088-1104, 2003.

Kubota, T., Shige, S., Hashizume, H., Aonashi, K., Takahashi, N., Seto, S., Hirose, M., Takayabu, Y. N., Nakagawa, K., Iwanami, K., Ushio, T., Kachi, M., and Okamoto, K.: Global precipitation map using satellite-borne microwave radiometers by the GSMaP Project: production and validation, IEEE Trans. Geosci. Remote Sens., 45, 2259-2275, 2007.

Laviola, S. and Levizzani, V.: Rain retrieval using $183 \mathrm{GHz}$ absorption lines, IEEE Proc. MicroRad 2008, 10th Specialist Meeting of Microwave Radiometry and Remote Sensing of the Environment, Firenze, 11-14 March, doi:10.1109/MICRAD.2008.4579505, 2008.

Laviola, S. and Levizzani, V.: Observing precipitation by means of water vapor absorption lines; a first check of the retrieval capabilities of the 183-WSL rain retrieval method, Italian J. Remote Sens., 41(3), 39-49, 2009.

Lensky, I. M. and Rosenfeld, D.: Clouds-Aerosols-Precipitation Satellite Analysis Tool (CAPSAT), Atmos. Chem. Phys., 8, 6739-6753, doi:10.5194/acp-8-6739-2008, 2008.

Levizzani, V., Schmetz, J., Lutz, H. J., Kerkmann, J., Alberoni, P. P., and Cervino, M.: Precipitation estimations from geostationary orbit and prospects METEOSAT second generation, Meteorol. Appl., 8, 23-41, 2001.

Liu, G. and Curry, J. A.: Precipitation characteristics in GreenlandIceland-Norwegian Seas determined by using satellite microwave data, J. Geophys. Res., 102, 13987-13997, 1997.

NRC: Earth Science and Application from Space: National Imperatives for the Next Decade and Beyond, The National Academic Press, Washington, DC, 2008.

Roebeling, R. A. and Holleman, I.: SEVIRI rainfall retrieval and validation using weather radar observations, J. Geophys. Res., 114, D21202, doi:21210.21029/22009JD012102, 2009.

Scofield, R. A. and Kuligowski, R. J.: Status and outlook of operational satellite precipitation algorithms for extreme precipitation events, Weather Forecast., 18, 1037-1051, 2003.
Shepherd, J. M., Pierce, H., and Negri, A. J.: Rainfall modification by major urban areas: observations from spaceborne rain radar on the TRMM satellite, J. Appl. Meteorol., 41, 689-701, 2002.

Sorooshian, S., Hsu, K.-L., Coppola, E., Tomassetti, B., Verdecchia, M., and Visconti, G.: Hydrological Modelling and the Water Cycle: Coupling the Atmospheric and Hydrological Models, Springer, Berlin, 291 pp., 2009.

Spencer, R. W., Goodman, H. M., and Hood, R. E.: Precipitation retrieval over land and ocean with SSM/I, Part I: Identification and characteristics of the scattering signal, J. Atmos. Ocean. Techn., 6, 254-273, 1989.

Stephens, G. L., Vane, D. G., Tanelli, S., Im, E., Durden, S., Rokey, M., Reinke, D., Partain, P., Mace, G. G., Austin, R., L'Ecuyer, T. S., Haynes, J., Lebsock, M., Suzuki, K., Waliser, D., Wu, D., Kay, J., Gettleman, A., Wang, Z., and Marchand, R.: The CloudSat mission: performance and early science after the first year of operation, J. Geophys. Res., 113, D00A18, doi:10.1029/2008JD009982, 2008.

Turk, F. J., Rohaly, G. D., Hawkins, J., Smith, E. A., Marzano, F. S., Mugnai, A., and Levizzani, V.: Meteorological applications of precipitation estimation from combined SSM/I, TRMM and infrared geostationary satellite data, in: Microwave Radiometry and Remote Sensing of the Earth's Surface and Atmosphere, edited by: Pampaloni, P. and Paloscia, S., VSP Int. Sci. Publ., Zeist, The Netherlands, 353-363, 2000.

Turk, F. J., Arkin, P., Ebert, E. E., and Sapiano, M.: Evaluating high-resolution precipitation products, B. Am. Meteorol. Soc., 89, 1911-1916, 2008.

Turk, J. and Bauer, P.: The International Precipitation Working Group and its role in the improvement of quantitative precipitation measurements, B. Am. Meteorol. Soc., 87, 643-647, 2006.

Villarini, G., Mandapaka, P. V., Krajewski, W. F., and Moore, R. J. Rainfall and sampling uncertainties: A rain gauge perspective, J. Geophys. Res., 113, D11102, doi:10.1029/2007JD009214, 2008.

Viltard, N., Burlaud, C., and Kummerow, C. D.: Rain retrieval from TMI brightness temperature measurements using a TRMM PRbased database, J. Appl. Meteorol. Climatol., 45, 455-466, 2006.

Wilheit, T. T., Chang, A. T. C., and Chiu, L. S.: Retrieval of monthly rainfall indices from microwave radiometric measurements using probability distribution functions, J. Atmos. Oceanic. Technol., 8, 118-136, 1991.

WMO: World Weather Watch - Twenty-second status report on implementation, ISBN 92-63-10986-9, WMO, Geneva, 60 pp., 2005.

Wolff, D. B., Marks, D. A., Amitai, E., Silberstein, D. S., Fisher, B. L., Tokay, A., Wang, J., and Pippitt, J. L.: Ground validation for the Tropical Rainfall Measuring Mission (TRMM), J. Atmos. Ocean. Techn., 22, 365-380, 2005.

Xie, P. and Arkin, P. A.: Global monthly precipitation estimates from satellite-observed outgoing longwave radiation, J. Climate, 11, 137-164, 1998.

Zipser, E. J., Cecil, D. J., Liu, C., Nesbitt, S. W., and Yorty, D. P.: Where are the most intense thunderstorms on Earth?, B. Am. Meteorol. Soc., 87, 1057-1071, 2006. 